\title{
Synchronicity of historical dry spells in the Southern Hemisphere
}

\author{
D. C. Verdon-Kidd and A. S. Kiem \\ Environmental and Climate Change Research Group, School of Environmental and Life Sciences, Faculty of Science and IT, \\ University of Newcastle,Newcastle, Australia
}

Correspondence to: D. C. Verdon-Kidd (danielle.verdon@ newcastle.edu.au)

Received: 11 November 2013 - Published in Hydrol. Earth Syst. Sci. Discuss.: 2 December 2013

Revised: - - Accepted: 4 April 2014 - Published: 18 June 2014

\begin{abstract}
A shift in climate occurred during the mid-1970s that affected the hydroclimate of the Southern Hemisphere resulting in drying trends across continental regions including Australia, New Zealand and southern and western Africa. There is also anecdotal evidence of other periods of climatic synchronicity in the Southern Hemisphere (e.g., the 1920s and 1940s), indicating that the mid-1970s event may not be anomalous. This paper identifies periods within the last $\sim 120$ years using statistical analysis where dry spells (in terms of annual to multi-decadal rainfall deficiencies) have coincided across the continental Southern Hemisphere in order to characterize temporal consistency. It is shown that synchronicity of dry spells is (a) most likely common over the last 120 years and (b) associated with changes in the large-scale climate modes of the Pacific, Indian and Southern Oceans. Importantly, the findings presented in this paper have marked implications for drought management and drought forecasting studies in the Southern Hemisphere.
\end{abstract}

\section{Introduction}

A number of continental regions in the Southern Hemisphere have experienced a change in climate since the mid-1970s. For example, southwest Western Australia is experiencing an extended dry spell that began in the mid-1970s, where austral winter (June-August) rainfall totals have decreased by approximately $20 \%$ (IOCI, 2002). Further, Van Ommen and Morgan (2010) reported a significant inverse correlation between the records of precipitation at Law Dome, East Antarctica and the southwest of Western Australia over the instrumental period. In particular, since the mid-1970s rainfall has increased at Law Dome, while rainfall has decreased in the southwest of Western Australia. The mid-1970s also corresponds to a period of change in climate for eastern Australia due to changes in ocean-atmospheric processes over the Pacific Ocean (i.e., the El Niño-Southern Oscillation (ENSO) and the Interdecadal Pacific Oscillation (IPO)), which have resulted in more frequent droughts (Mantua et al., 1997; Power et al., 1999; Wang and An, 2001; Kiem et al., 2003; Kiem and Franks, 2004; Verdon and Franks, 2006). A similar shift in New Zealand's climate around 1976 has also been identified, with the period 1976-1994 characterized by annual rainfall decreases in the north of the North Island and increases in much of the South Island (Salinger and Mullan, 1999). Further, in Southern Africa, overall moist conditions were reported between 1960 and 1970 and since then a switch to drier conditions has been noted (Ngongondo, 2006).

There is also evidence of significant climate shifts in the Southern Hemisphere during the mid-1940s and mid-1920s (e.g., Mantua et al., 1997; Power et al., 1999; Kiem et al., 2003; Kiem and Franks, 2004; Verdon and Franks, 2006), highlighting the fact that the mid-1970s climate shift is not likely to be an isolated event. This apparent connection between rainfall in Australia and East Antarctica, along with the similar timing of climate shifts in Southern Africa and New Zealand, suggests the possibility of synchronicity in dry spells across the Southern Hemisphere. The aim of this paper is therefore to characterize this synchronicity over the last 120 years (a period when rainfall data is available for the continental regions) and to determine the climate-driving mechanism that may contribute to this synchronicity. 


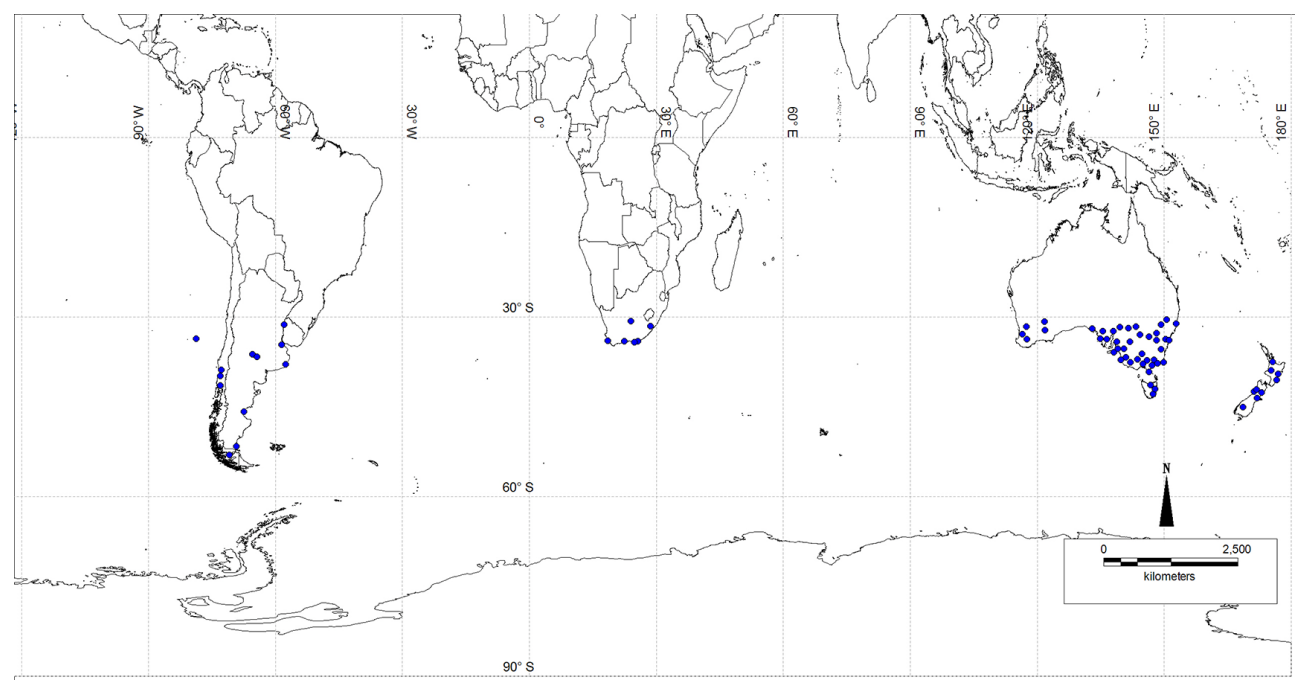

Figure 1. Location of 73 monthly rainfall stations used in this analysis (blue circles).

\section{Data}

\subsection{Gridded data}

The NCEP/NCAR (National Centers for Environmental Prediction and the National Center for Atmospheric Research) Reanalysis global gridded data sets, available from the US National Oceanic and Atmospheric Administration (NOAA, www.esrl.noaa.gov/psd/), are used to study the 1970s climate shift in the Southern Hemisphere. The NCEP/NCAR Reanalysis data is derived from a global spectral model with a grid resolution of 2.5 degree latitude $\times 2.5$ degree longitude global $(144 \times 73$ grids $)$. The data set, available for various atmospheric and hydrological variables, was developed using a state-of-the-art analysis/forecast system to perform data assimilation using past data from 1948 to the present. However, as with all reanalysis data, this data has various limitations, particularly in the Southern Hemisphere where historical recorded data tends to be sparse (see Trenberth and Guillemot, 1998). In order to overcome this, station-based data has been used to ground truth observations based on the reanalysis data (described in the following section).

\subsection{Station-based monthly rainfall data}

Station-based observed rainfall data from continental regions south of $30^{\circ}$ (Fig. 1) were obtained from the following data sources:

- Australia - Monthly station-based rainfall data was obtained from the Australian Bureau of Meteorology (www.bom.gov.au/climate/data/weather-data. shtml). Data chosen for analysis was at least $95 \%$ complete and covered the period 1900-2009.

- New Zealand - Daily station data was obtained from the National Climate Database of the National Insti- tute of Water and Atmospheric Research (NIWA, http:// cliflo.niwa.co.nz/). Data chosen for analysis was at least $95 \%$ complete and covered the period 1920-present. An additional station was chosen for analysis (located at Reefton on the west coast of New Zealand) that contained daily data from 1948 onwards in order to sufficiently represent the west coast of New Zealand. Daily data was aggregated to monthly data prior to analysis.

- South America and South Africa - Monthly rainfall data for South America and South Africa was obtained from the Global Historical Climatology Network (GHCN, http://www.ncdc.noaa.gov/data-access/ land-based-station-data/land-based-datasets/

global-historical-climatology-network-ghen). The historical GHCN data has previously undergone a rigorous quality assurance review (including preprocessing checks on source data, time series checks that identify spurious changes in the mean and variance, spatial comparisons that verify the accuracy of the climatological mean and the seasonal cycle, and neighbor checks that identify outliers from both a serial and a spatial perspective). Despite the level of quality assurance, the rainfall data available through the GHCN for South America and South Africa is not as complete as data from Australia and New Zealand, with the more recent data being particularly sparse. Station data included varies in length, with all stations containing data from at least 1920 to 2009 (however, two additional stations from Argentina were included that contained data from 1931 onwards (at Puerto Deseado Aero and Rio Gallegos Aero) in order to improve the spatial coverage of the east coast of South America). 

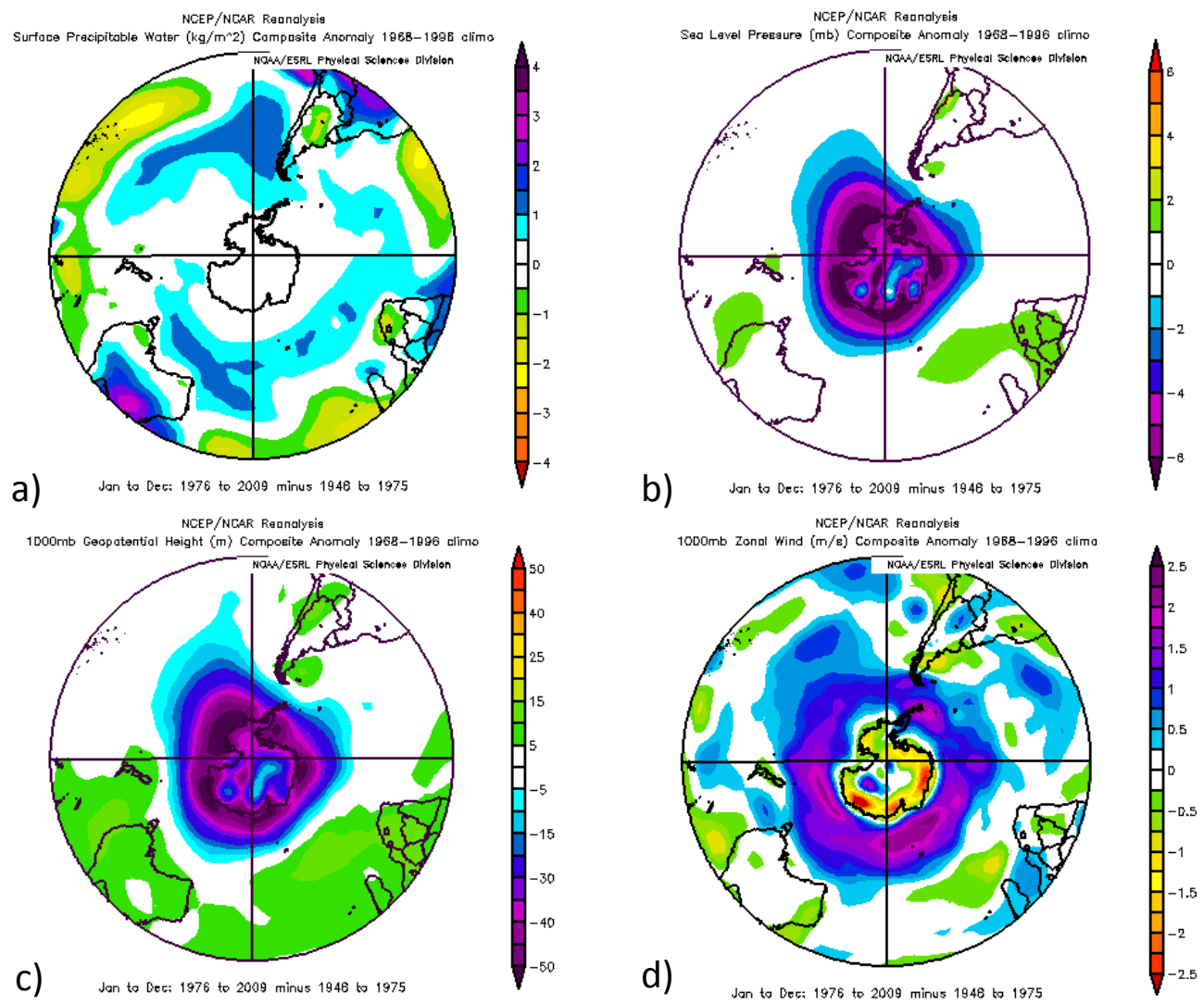

Figure 2. Differences in (a) annual surface precipitable water, (b) sea level pressure, (c) geopotential height and (d) zonal wind anomalies during the period 1976-2009 compared to 1948-1975.

Station data was sourced south of $30^{\circ}$ as this is the prime region where interdecadal variability in flood and drought cycles have historically been observed, including the mid-1970s climate shift discussed in the Introduction (see Verdon-Kidd et al., 2013).

\subsection{Indices of large-scale climate modes}

The four dominant large-scale climate modes operating in the Southern Hemisphere are

- ENSO (Chiew et al., 1998; Kiem and Franks, 2001; Verdon et al., 2004), which in this study is represented by the Oceanic Niño Index (ONI) from the United States National Oceanic and Atmospheric Administration (NOAA) Climate Prediction Centre (CPC) (www. cpc.ncep.noaa.gov). The ONI is a 3 month running mean of ERSST.v3b sea surface temperature anomalies in the Niño 3.4 region, centered on 30 year base periods updated every 5 years. For historical purposes cold (La Niña) and warm (El Niño) episodes are defined when the ONI exceeds the threshold of $\pm 0.5^{\circ}$ for a minimum of 5 consecutive over-lapping seasons.
- IPO (Power et al., 1999; Kiem et al., 2003; Verdon et al., 2004; Power and Colman, 2006), a low frequency (15-35 years) pattern of variability of the tropical and extra-tropical Pacific ocean (refer to Power et al., 1999 for details). Folland et al. (1999) derived an index of IPO variability using a low-pass filter of near-global sea surface temperatures, while Power et al. (1999) applied a spectral filter with a 13 year cut-off to the raw IPO to generate a smoothed (or slowly varying) IPO time series. Both the raw and the smoothed time series of Power et al. (1999) are used in this study in order to identify epochs of positive and negative IPO.

- Indian Ocean Dipole (IOD; Saji et al., 1999; Ashok et al., 2003; Verdon and Franks, 2005), which in this study is represented by the Dipole Model Index (DMI) developed by Saji et al. (1999), defined as the difference in sea surface temperature anomaly between the tropical western Indian Ocean $\left(50-70^{\circ} \mathrm{E}, 10^{\circ} \mathrm{S}-10^{\circ} \mathrm{N}\right)$ and the tropical southeastern Indian Ocean $\left(90-110^{\circ} \mathrm{E}, 10^{\circ} \mathrm{S}-\right.$ Equator).

- Southern Annular Mode (SAM; Thompson and Wallace, 2000; Thompson et al., 2000; Ho et al., 2012), whereby in this study the NOAA CPC version of the 
Antarctic Oscillation (AAO) is used when it exists (i.e., from 1979 onwards) and the Thompson and Wallace (2000) AAO data is used prior to that (1948 to 1978). Overlapping periods (1979 to 2002) of the two versions of the AAO were compared and the difference found to be negligible $\left(R^{2}=0.95, N=288\right)$.

\section{Synchronicity in Southern Hemisphere climate since the mid-1970s}

An analysis of changes in the Southern Hemisphere climate was carried out using the gridded data described in Sect. 2.1. Figure 2a shows, for the period 1976-2009, a clear decrease in annual precipitable water in the southwest and southeast of Australia, New Zealand and central South America. This decrease in precipitable water was also associated with an increase in sea level pressure (Fig. 2b) and geopotential height (Fig. 2c) over continental regions located between 30 and $45^{\circ}$. The anomalous high pressure since the mid-1970s would naturally manifest in reduced rainfalls in these regions. The observed increase in zonal wind speeds (Fig. 2d) would also have the effect of pulling storm tracks further south; hence stations located south of $45^{\circ}$ show an increase in rainfall, while mid-latitude stations ( 30 to $45^{\circ}$ ) have experienced a decrease in rainfall (consistent with CSIRO, 2012).

\section{Synchronicity in dry spells across the Southern Hemisphere since 1900}

Monthly station-based rainfall data (described in Sect. 2.2) were converted to annual totals and ranked from lowest to highest for each individual station. This was carried out for 1,2, 5 and 10-year running means. The lowest five rainfall epochs (dry spells) during the period 1900-2009 were then compared for each station to identify any temporal consistencies (Fig. 3).

Figure 3 shows that dry spells display a strong degree of consistency across the mid-latitudes for the 1 year through the 10 year rainfall rankings. It is also clear that there does not appear to be any monotonically increasing trend in dry spells throughout the last century. Rather, based on the results presented here, it appears that overall the period 1910 through to 1950 was dry for regions south of $30^{\circ}$ (particularly the mid-1920s to mid-1940s), followed by a relatively wet period (i.e., absence of prolonged dry periods) from 1950 through to 1980 and a return to dry thereafter (based on the 5 and 10 rainfall rankings). This is consistent with studies that suggest cyclic activity in wet and dry periods in the historical records (e.g., Erskine and Warner, 1988; Verdon-Kidd and Kiem, 2009; Hastenrath and Polzin, 2011). Research presented in CSIRO (2012) suggests that drought periods are more likely during periods of accelerated global warming (and increasing intensity of the subtropical ridge), rather than during periods when the rate of global warming is lower. The
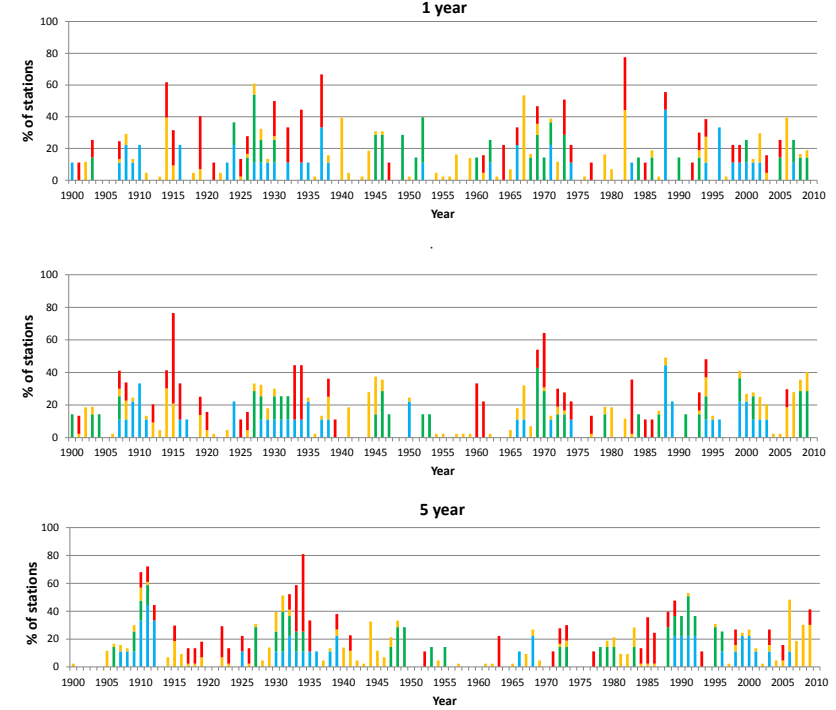

10 year

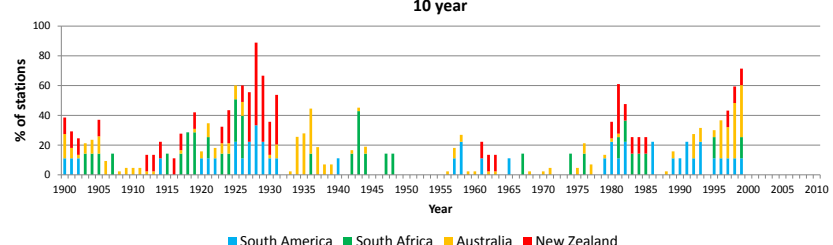

Figure 3. Total percentage of stations for each region where the 110 year cumulative rainfall was among the five lowest during the period 1900-2009.

analysis of dry spells presented in this paper is consistent with this theory, given that the rate of global warming is understood to be lower during the period 1950 through to 1980 (CSIRO, 2012), when dry spells were also shown to be less prevalent. However, given that this also corresponds to a time period when the IPO (a dominant driver of flood and drought cycles in Australia and elsewhere) was predominantly negative, along with more frequent La Niña and less frequent El Niño events, it is difficult to ascertain the true cause of these multi-decadal cycles of elevated drought risk. This is explored further in Sect. 6.

The occurrence of shorter dry spells (i.e., 1 or 2 year) is also distributed across the record (Fig. 3), with no evidence of a monotonically increasing or decreasing trend. Individual years of significant synchronicity include 1902/03 (Australia, New Zealand, South Africa), 1914/15 (Australia, New Zealand), 1940 (Australia), 1967/68 (Australia, New Zealand), 1982/83 (Australia, New Zealand, South America), 1993/94 (all countries), 2001/02 (all countries), and 2005/06 (Australia, New Zealand, South Africa). 


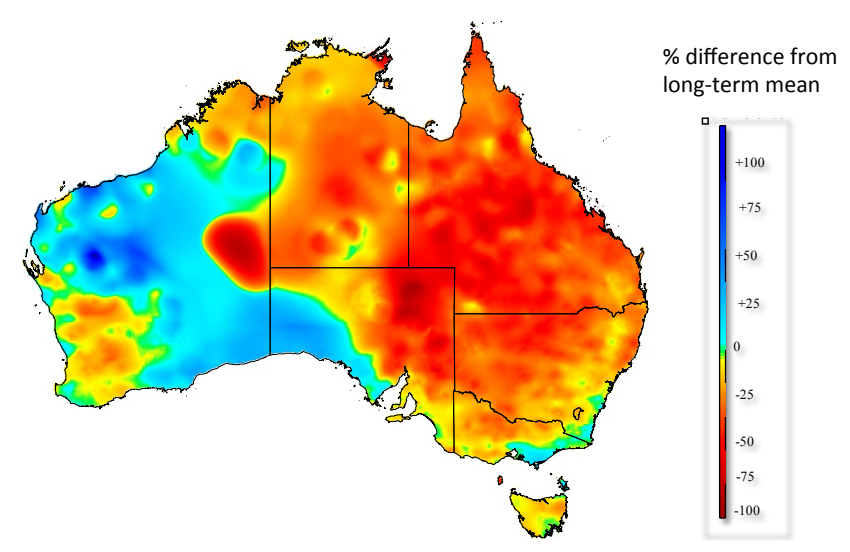

Figure 4. Spatial extent (in terms of rainfall anomalies) of the Federation Drought ( 1895-1902) in Australia (from Verdon-Kidd and Kiem 2009).

\section{A case study - was the Federation Drought, experienced in Australia 1895-1902, just confined to Australia?}

Expansion of agricultural regions into regional Australia occurred in the late 1800 s after a series of promising rainfall years. Following this, a severe drought gripped northern and eastern Australia, which lasted from 1895-1902 as shown in Fig. 4 (Verdon-Kidd and Kiem, 2009). The Federation Drought, as it became known, was the most severe (in terms of rainfall deficits) of Australia's three iconic protracted droughts, including the Big Dry $(\sim 1997-2010)$ and the World War II Drought ( 1937-1945) (Verdon-Kidd and Kiem, 2009). Station data with records dating back to 1890 were analyzed to determine if the Federation Drought was confined to Australia, or if this dry spell was also synchronous across parts of the Southern Hemisphere (Fig. 5).

Based on the analysis presented in Fig. 5, it appears that the east coast of South America, the east coast of South Africa, southwest and southeast of Australia and southern New Zealand all experienced a dry spell during the 8-year "Federation Drought" period ( 1895-1902). This result suggests a reduction in easterly flow south of $30^{\circ}$ during this time, a condition often associated with El Niño conditions (note that the Federation Drought was primarily driven by an extended El Niño phase (Verdon-Kidd and Kiem, 2009)). While the exact spatial extent of this dry spell is not clear (due to the reduced number of stations recording rainfall during this time) the results imply a degree of temporal consistency during this time for many regions of the Southern Hemisphere.
Table 1. Climate drivers during years when dry events coincide across the Southern Hemisphere.

\begin{tabular}{cllll}
\hline Year & ENSO & IPO & DMI & SAM \\
\hline $1902 / 03$ & El Niño & Positive & Positive & Negative \\
$1914 / 15$ & El Niño & Negative & Neutral & Negative \\
$1940 / 41$ & El Niño & Positive & Positive & Negative \\
$1967 / 68$ & Neutral & Negative & Positive & Negative \\
$1982 / 83$ & El Niño & Positive & Positive & Positive \\
$1993 / 94$ & El Niño & Positive & Positive & Positive \\
$2001 / 02$ & El Niño & Neutral & Negative & Neutral \\
$2005 / 06$ & El Niño & Negative & Neutral & Positive \\
\hline
\end{tabular}

\section{Climate-driving mechanisms forcing hydroclimatic synchronicity}

As stated in Sect. 2.3, the main climate-driving mechanisms for the Southern Hemisphere are ENSO, IPO, IOD and SAM. For example, ENSO control on climate is known to extend to Australia, South America, Africa and New Zealand (e.g., Ropelewski and Halpert, 1996). Similarly, Indian Ocean sea surface temperature variability has been shown to affect both Australian and African rainfall (Reason, 1999; Saji et al., 1999; Ansell et al., 2000; Ashok et al., 2003; Verdon and Franks, 2006). Table 1 shows the state of the main climate drivers during periods of short-term synchronicity in the Southern Hemisphere, as identified in Fig. 3. Time series of ENSO, IPO, IOD and SAM are shown in Fig. 6 (see Sect. 2.3 for a description of the indices) along with the common protracted dry epochs across the Southern Hemisphere.

It is clear from Table 1 that ENSO plays a key role in driving Southern Hemisphere synchronicity with seven out of the eight short-term simultaneous dry spells occurring during an El Niño event (noting that none occur during La Niña). This is not surprising given the significant role that ENSO plays in controlling climate around the globe (Ropelewski and Halpert, 1996). While the Pacific Ocean is clearly a major driver, Table 1 shows that short-term droughts can occur against a background of either phase of the IPO (i.e., it is the shorter ENSO cycles that dominate annual episodes). It also appears that the Indian and Southern Oceans have a significant influence on this synchronicity at the annual scale. For example, the DMI is positive during five out of the eight short-term dry spells (with only one negative DMI event). Further, during the four more recent dry periods SAM has been predominantly positive (corresponding to higher pressure between 30 and $45^{\circ}$ South and a southward shift in the westerly winds towards Antarctica) pointing towards the possibility that the SAM may be becoming more important in regulating droughts as it continues to trend positive (e.g., $\mathrm{Ar}$ blaster and Meehl, 2006).

Figure 6 highlights some important findings regarding Southern Hemisphere synchronicity on decadal to multidecadal scales. In particular, it is clear that the Pacific Ocean 


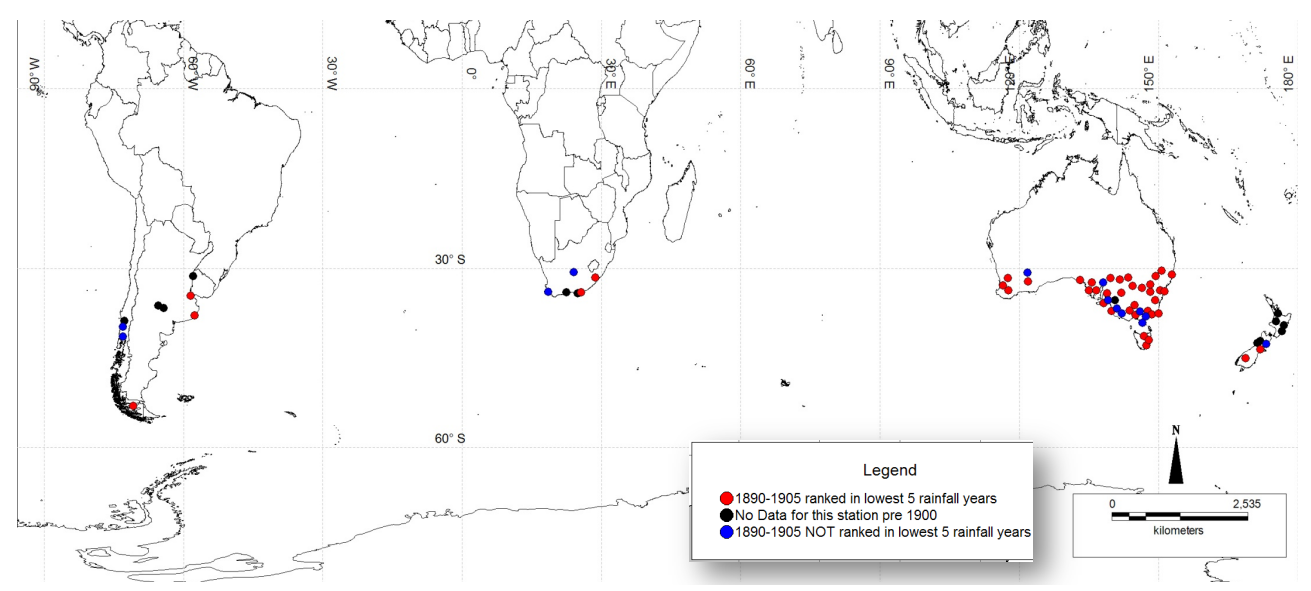

Figure 5. Stations where the period 1890-1905 was listed in the top five lowest rainfall years (shown in red).

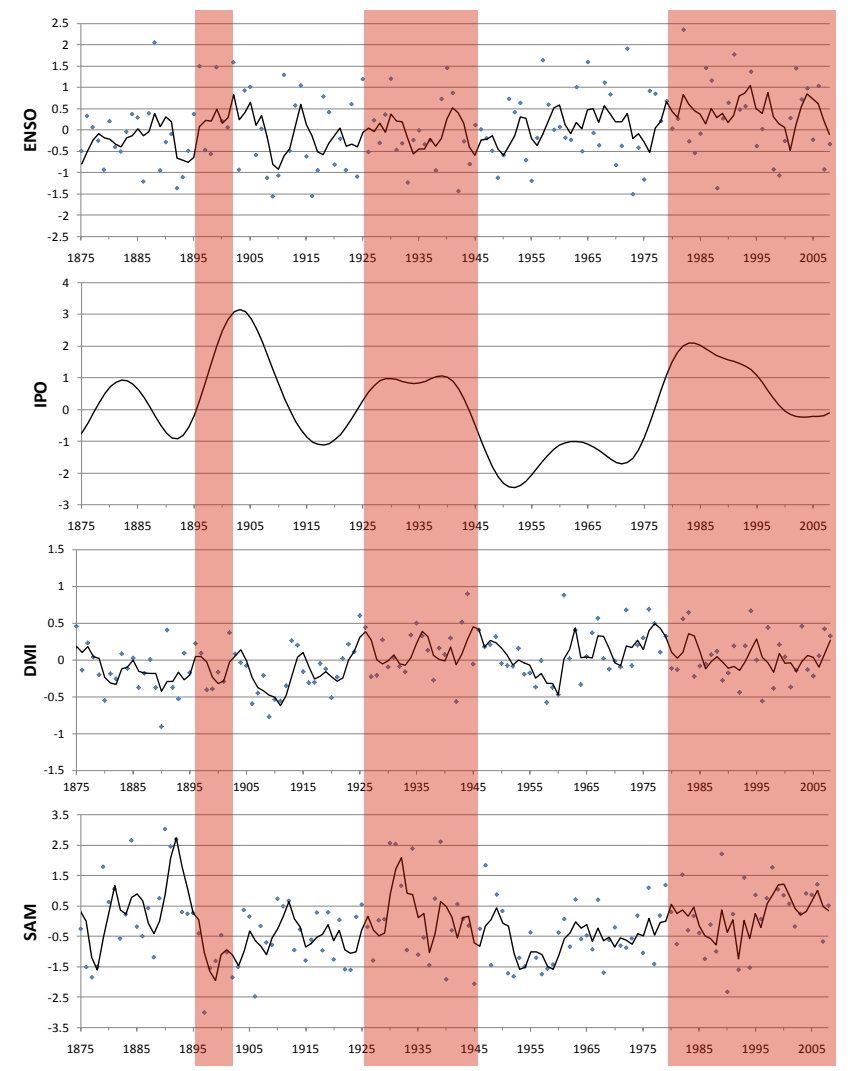

Figure 6. Historical time series of ENSO, IPO, DMI and SAM. Dots represent the mean "annual" value for each index, solid line is the 3 year moving average, red shaded regions indicate the common dry periods across the Southern Hemisphere.

is a dominant driver of protracted dry episodes in the Southern Hemisphere, with the IPO being in a positive phase with an absence of La Niña events during all protracted dry events (as per Kiem and Franks, 2004). However, it is also clear that the Southern and Indian Oceans are also important drivers of this synchronicity. For example, during two of the three extended dry periods shown here the SAM is persistently positive. Note that while SAM is not shown to be positive during the Federation Drought $(\sim 1895-1902)$ there is some question over the validity of the index used to represent SAM during the earlier part of the record (Ho et al., 2012); further, the influence of the SAM is very seasonally dependent for Australian rainfall (Hendon et al., 2007), with opposite effects on rainfall in summer versus winter, which may be negated when analyzing annual rainfall. As shown in Figure 6 the DMI was predominantly positive during the dry period that occurred between $\sim 1925-1945$, contributing to the synchronicity observed during this period, particularly between Australia and South Africa.

\section{Discussion and conclusions}

In this study a number of common periods of hydroclimatic variability in the Southern Hemisphere have been identified since the late 1800 s, on a short timescale (1 year) through to multi-decadal timescales. For example, across the Southern Hemisphere the period 1910-1950 appears dry on average, followed by a wetter period (absence of dry events) between 1950 and 1970/80, when a return to dry conditions occurred for much of the continental Southern Hemisphere. Furthermore, the analysis presented here indicates that the Federation Drought $(\sim 1895-1902)$, an iconic drought in Australia's history, was not limited to Australia, although the exact spatial extent across the Southern Hemisphere is unclear. It was also shown that the state of the Pacific Ocean (in terms of ENSO and IPO) is crucial in driving large-scale, long-term synchronicity of dry epochs. However, the SAM and IOD also play an important role in modulating both short- and long-term dry events.

Droughts are, and always will be, part of the hydroclimate (particularly of the mid-latitudes) and it is impossible 
to prevent these natural disasters from occurring. The multifaceted nature of droughts and the complexities associated with securing the world's water resources in the face of a highly uncertain future requires innovative thinking to improve our understanding and reduce our vulnerability to climate extremes. Therefore, an adequate understanding of the mechanisms that cause enhanced risk periods is essential to effectively manage and minimize the damage associated with droughts when they do occur. This paper represents one step towards identifying controls on major drought periods in the Southern Hemisphere with the aim being to (a) better understand historical and baseline levels of drought risk and (b) better understand which controls are important, and characterize their influence, to inform seasonal to multi-decadal climate forecasting and modeling activities. Any advancement in the ability to forecast, or better model, the onset and termination of drought would clearly benefit a wide spectrum of the community, industry and economic sectors.

Acknowledgements. This study was partially funded by the Victorian Department of Sustainability and Environment (DSE), now known as the Victorian Department Environment and Primary Industries (DEPI). The authors would especially like to thank Rae Moran (DSE/DEPI) for reviewing an earlier version of this work.

Edited by: M. Werner

\section{References}

Arblaster, J. M. and Meehl, G. A.: Contributions of External Forcings to Southern Annular Mode Trends, J. Climate, 19, 2896 2905, doi:10.1175/JCLI3774.1, 2006.

Ashok, K., Guan, Z., and Yamagata, T.: Influence of the Indian Ocean Dipole on the Australian winter rainfall, Geophys. Res. Lett., 30, 1821, doi:10.1029/2003GL017926, 2003.

Chiew, F. H. S., Piechota, T. C., Dracup, J. A., and McMahon, T. A.: El Niño Southern Oscillation and Australian rainfall, streamflow and drought - links and potential for forecasting, J. Hydrol., 204, 138-149, 1998.

CSIRO: Climate and water availability in south-eastern Australia: A synthesis of findings from Phase 2 of the South Eastern Australian Climate Initiative (SEACI), 2012.

Erskine, W. D. and Warner, R. F.: Geomorphic effects of alternating flood and drought dominated regimes on a NSW coastal river, in: Fluvial Geomorphology of Australia, edited by: Warner, R. F., 223-244, Academic Press, Sydney, 1988.

Hastenrath, S. and Polzin, D.: Long-term variations of circulation in the tropical Atlantic sector and Sahel rainfall, Int. J. Climatol., 31, 649-655, doi:10.1002/joc.2116, 2011.

Hendon, H. H., Thompson, D. W. J., and Wheeler, M. C.: Australian rainfall and surface temperature variations associated with the Southern Hemisphere Annular Mode, J. Climate, 20, 2452-2467, 2007

Ho, M., Kiem, A. S., and Verdon-Kidd, D. C.: The Southern Annular Mode: a comparison of indices, Hydrol. Earth Syst. Sci., 16, 967-982, doi:10.5194/hess-16-967-2012, 2012.
IOCI: Climate variability and change in south west Western Australia, Indian Ocean Climate Initiative (IOCI) Panel, Perth, Australia, 2002.

Kiem, A. S. and Franks, S. W.: On the identification of ENSOinduced rainfall and runoff variability: a comparison of methods and indices, Hydrol. Sci. J., 46, 715-727, 2001.

Kiem, A. S. and Franks, S. W.: Multi-decadal variability of drought risk - Eastern Australia, Hydrol. Process., 18, 2039-2050, 2004.

Kiem, A. S., Franks, S. W., and Kuczera, G.: Multi-decadal variability of flood risk, Geophys. Res. Lett., 30, 1035, doi:10.1029/2002G1015992, 2003.

Mantua, N. J., Hare, S. R., Zhang, Y., Wallace, J. M., and Francis, R. C.: A Pacific interdecadal climate oscillation with impacts on salmon production, B. Am. Meteorol. Soc., 78, 1069-1079, 1997.

Ngongondo, C. S.: An analysis of long-term rainfall variability, trends and groundwater availability in the Mulunguzi river catchment area, Zomba mountain, Southern Malawi, Quaternary Int., 148, 45-50, 2006.

Power, S. and Colman, A.: Multi-year predictability in a coupled general circulation model, Clim. Dynam., 26, 247-272, 2006.

Power, S., Casey, T., Folland, C., Colman, A., and Mehta, V.: Interdecadal modulation of the impact of ENSO on Australia, Clim. Dynam., 15, 319-324, 1999.

Ropelewski, C. F. and Halpert, M. S.: Quantifying Southern Oscillation - precipitation relationships, J. Climate, 9, 1043-1059, 1996.

Saji, N. H., Goswami, B. N., Vinayachandran, P. N., and Yamagata, T.: A dipole mode in the tropical Indian Ocean, Nature, 401, 360363, 1999.

Salinger, M. J. and Mullan, A. B.: New Zealand climate: Temperature and precipitation variations and their links with atmospheric circulation 1930-1994, Int. J. Climatol., 19, 1049-1071, 1999.

Thompson, D. W. J. and Wallace, J. M.: Annular modes in the extratropical circulation, part I: month-to-month variability, J. Climate, 13, 1000-1016, 2000.

Thompson, D. W. J., Wallace, J. M., and Hegerl, G. C.: Annular modes in the extratropical circulation, part II: Trends, J. Climate, 13, 1018-1036, 2000

Trenberth, K. E. and Guillemot, C. J.: Evaluation of the atmospheric moisture and hydrological cycle, Clim. Dynam., 14, 213-231, 1998.

Van Ommen, T. D. and Morgan, V.: Snowfall increase in coastal East Antarctica linked with southwest Western Australian drought, Nat. Geosci., 3, 267-272, doi:10.1038/NGEO761, 2010.

Verdon, D. C. and Franks, S. W.: Indian Ocean sea surface temperature variability and winter rainfall: Eastern Australia, Water Resour. Res., 41, W09413, doi:10.01029/02004WR003845, 2005.

Verdon, D. C. and Franks, S. W.: Long-term behaviour of ENSO: Interactions with the PDO over the past 400 years inferred from paleoclimate records, Geophys. Res. Lett., 33, L06712, doi:10.1029/2005GL025052, 2006

Verdon, D. C., Wyatt, A. M., Kiem, A. S., and Franks, S. W.: Multidecadal variability of rainfall and streamflow - Eastern Australia, Water Resour. Res., 40, W10201, doi:10.1029/2004WR003234, 2004. 
Verdon-Kidd, D. C. and Kiem, A. S.: Nature and causes of protracted droughts in southeast Australia: Comparison between the Federation, WWII, and Big Dry droughts, Geophys. Res. Lett., 36, L22707, doi:10.1029/2009GL041067, 2009.

Verdon-Kidd, D. C., Kiem, A. S., and Moran, R.: Links between the Big Dry in Australia and hemispheric multi-decadal climate variability - implications for water resource management, Hydrol. Earth Syst. Sci., 18, 2235-2256, doi:10.5194/hess-18-22352014, 2014.
Wang, B. and An, S.: Why the properties of El Niño changed during the late 1970s, Geophys. Res. Lett., 28, 3709-3712, 2001. 